\title{
Remuneração nos serviços no Brasil: o contraste entre funcionários públicos e privados ${ }^{1}$
}

\author{
Daniela Verzola Vaz $^{2}$ \\ Rodolfo Hoffmann ${ }^{3}$
}

\begin{abstract}
Resumo
Utilizando dados da PNAD, o trabalho investiga o comportamento do hiato de rendimentos entre funcionários públicos e empregados do setor privado com carteira assinada, ocupados no setor terciário, de 1992 a 2005. São ajustadas, em separado, equações de rendimento, a fim de apontar as diferenças no efeito de vários fatores (idade, sexo, escolaridade, etc.) sobre o salário de cada categoria. Mediante o emprego da metodologia de Blinder-Oaxaca identifica-se quanto do diferencial de rendimentos entre os dois grupos se deve a diferenças na capacitação individual dos trabalhadores e quanto está associado a outros fatores, analisando como essa decomposição evoluiu ao longo do período 1992-2005. Um resultado importante é o crescimento do hiato de rendimentos entre os dois grupos, especialmente da parcela não explicada pelas diferenças na capacitação dos empregados.
\end{abstract}

Palavras-chave: Salários; Desigualdade de renda; Setor público; Mercado de trabalho.

\section{Abstract \\ Earnings in the tertiary sector in Brazil: the contrast between public and private workers}

Using data from an annual household survey (PNAD), this study analyses the behavior of the wage gap between public and private formal workers from the tertiary sector in Brazil from 1992 to 2005 . Earnings equations are estimated separately for these two groups. Such equations allow us to evaluate the effect of age, gender, schooling, color (race), position in the occupation, weekly working time and other factors on earnings of each category. Blinder-Oaxaca methodology reveals how much of the wage gap between the workers of both sectors is due to differences in productive endowments and how much is due to other factors, such as the existence of segmentation between the public and the private labor market in Brazil. An important result is the increase of the wage gap between the two groups of workers, mainly of the part that can not be explained by workers' productive endowments.

Key words: Wage differentials; Income inequality; Public sector; Labor markets. JEL D31, J31, J45.

\section{Introdução}

Apesar de explicar uma pequena parcela da desigualdade total da distribuição de renda no Brasil, o diferencial de rendimentos entre funcionários

(1) Trabalho recebido em setembro de 2006 e aprovado em março de 2007.

(2) Doutoranda em Teoria Econômica do Instituto de Economia da Universidade Estadual de Campinas - Unicamp. E-mail: < danivvaz@ yahoo.com.br>.

(3) Professor do Instituto de Economia da Unicamp. E-mail: <rhoffman@eco.unicamp.br>. 
públicos e empregados do setor privado é importante tema de estudo na área de economia aplicada. Primeiro, porque a comparação entre rendimentos e produtividade de funcionários públicos e privados é comumente empregada em discussões sobre a eficiência do setor público e o papel do Estado na economia. Segundo, porque este hiato de rendimentos ampliou-se na última década, despertando o interesse em investigar seus determinantes.

Os objetivos deste trabalho são, além de apontar a existência de um hiato de rendimentos entre funcionários públicos e empregados em serviços do setor privado com carteira assinada, mapear sua ampliação entre 1992 e 2005 e investigar suas causas.

Pretende-se identificar quanto do diferencial de rendimentos entre as duas categorias advém de diferenças na capacitação individual dos trabalhadores e quanto está associado a outros fatores. Ademais, o trabalho investiga como essa relação se comportou no período de 1992 a 2005.

Especial atenção é conferida aos efeitos da escolaridade sobre o rendimento dos dois grupos, com o objetivo de explicar o papel desempenhado por esse atributo na ampliação do diferencial de rendimentos em questão.

Uma das ferramentas de pesquisa utilizadas é a decomposição de BlinderOaxaca, comumente aplicada no estudo da discriminação salarial por gênero e por raça.

O artigo está organizado em quatro partes, além desta. Na primeira seção, são retomadas as diferenças apontadas em trabalhos anteriores entre os perfis produtivos e remuneratórios de trabalhadores públicos e privados. A seção seguinte é destinada à apresentação da base de dados e da metodologia de trabalho. Na terceira seção são apresentados e discutidos os resultados. Uma vez constatada a ampliação do hiato salarial entre funcionários públicos e empregados do setor privado com carteira assinada no período de 1992 a 2005, procura-se compreender as possíveis causas da existência e da evolução desse diferencial. Por fim, são sumariados os principais resultados alcançados e apresentadas as conclusões.

\section{Diferenças de escolaridade e rendimento entre os setores público e privado}

As comparações já realizadas entre os mercados de trabalho público e privado permitem afirmar que o perfil dos servidores públicos é qualitativamente melhor que o observado entre os trabalhadores do setor privado, pois tanto seu nível de escolaridade como sua experiência (esta última captada pelo número de anos de serviço na ocupação corrente) são, em média, mais elevados. 
Ramalho e Urani (1995), por exemplo, observam que a participação da administração pública na ocupação total foi muito mais elevada para os trabalhadores qualificados que para os não qualificados, na década de 1980. Neste período, a qualidade dos empregados da administração pública, em termos de grau de escolaridade, foi, de fato, muito superior à do restante da economia: em 1981, a metade dos funcionários públicos tinham 9 ou mais anos de estudo; em 1990, este valor era de aproximadamente $56 \%$, ao passo que o número médio de anos de estudo da PEA ocupada era inferior a 5.

Marconi (2003) constata que, entre 1993 e 1999, a participação relativa das pessoas com quatro ou menos anos de estudo no setor público reduziu-se (à exceção dos servidores celetistas), enquanto cresceu a dos trabalhadores com 12 ou mais anos de estudo (à exceção do grupo dos militares, o qual apresenta relativa estabilidade neste segmento). Para os trabalhadores do setor privado e servidores municipais, crescimento proporcionalmente maior foi observado no grupo das pessoas que possuem entre 9 e 11 anos de estudo; para os servidores estaduais e federais estatutários, no grupo de funcionários que possuem 12 anos ou mais de estudo.

As características dos integrantes do mercado de trabalho dos servidores públicos municipais são as que mais se aproximam das observadas no setor privado. Tanto a distribuição percentual dos anos de estudo como o número médio de anos de serviço confirmam essa observação. Na interpretação de Marconi (2003), essa semelhança pode ser explicada por uma possível influência relevante, sobre os dois grupos, das condições econômicas e sociais locais.

No que se refere à qualidade dos postos de trabalho, o autor constata que esta é superior no setor público, onde as ocupações são, em média, menos operacionais e demandam maior nível de qualificação dos trabalhadores.

Em relação à remuneração, Ramalho e Urani (1995) observam que os salários reais médios pagos no setor público, ao longo da década de 1980, foram $45 \%$ superiores àqueles pagos no setor privado. Introduzindo controles para o nível educacional, entretanto, estes autores revelam que este diferencial de rendimentos favorável a funcionários públicos foi positivo apenas entre os trabalhadores com menos de 1 ano de estudo, sendo negativo (ou seja, favorável a empregados do setor privado) para todos os demais níveis educacionais e tão mais negativo quanto maior o número de anos de estudo.

Já em 1990, a administração pública pagava os pouco qualificados da mesma forma que o setor privado, enquanto o diferencial de rendimentos dos muito qualificados (favorável ao setor privado) havia caído significativamente. 
Portanto, a capacidade do funcionalismo público de preservar seu salário real foi muito maior entre os funcionários mais qualificados.

Combinando os dados sobre salários e sobre geração de emprego, os autores constatam que a administração pública foi responsável por mais de $1 / 5$ do total da renda do trabalho gerada ao longo da década como um todo. Para os trabalhadores com menos de 1 ano de estudo e para aqueles com mais de 11 anos de estudo, esta proporção superou os 30\%; para os trabalhadores que tinham de 5 a 8 anos de estudo ela foi de apenas $6,2 \%$.

Najberg et al. (2002), investigando a remuneração média dos trabalhadores do setor público no ano 2000, constatam que, para todos os Estados da Federação, a remuneração dos servidores públicos é superior à remuneração média do total do pessoal ocupado, extraída do Censo (IBGE). Em termos geográficos, o Estado com maior remuneração média para os trabalhadores da administração pública é o Distrito Federal (11,4 salários mínimos), seguido de Amapá, Rio de Janeiro, São Paulo e Roraima. Dos dez Estados com menor remuneração para os trabalhadores da administração pública, oito pertencem ao Nordeste. No que se refere às esferas de governo, os empregados das empresas estatais e os funcionários federais têm remuneração média maior que os estaduais, e estes, uma média maior que os funcionários municipais.

Marconi (2003) mostra que não só os salários médios pagos no setor público são superiores aos pagos no setor privado, como os diferenciais brutos (sem controles para características demográficas e produtivas) de salário médio entre o setor público e o privado aumentaram ao longo da década de 1990. Com exceção dos celetistas, o salário das demais categorias de servidores públicos apresentou crescimento maior que o registrado para os trabalhadores do setor privado entre 1993 e 1999.

Ao introduzir controles para características demográficas (gênero, cor e idade), produtivas (nível educacional e experiência no trabalho) e institucionais (grau de sindicalização e localização geográfica do trabalhador), este autor observa que os diferenciais salariais reduzem-se substancialmente em relação aos diferenciais brutos (sem qualquer tipo de controle relativo às características pessoais). Logo, as diferenças na composição da força de trabalho entre os dois setores explicam uma parcela significativa do diferencial bruto de salário (não controlado). Porém, o diferencial salarial permanece positivo para os funcionários públicos na maioria dos casos analisados — é negativo, entre 1993 e 1996, para os servidores municipais e estatisticamente nulo, apenas em 1999, para os municipais. Assim, mesmo após a inclusão de diversos tipos de controle, os salários no setor público são, em geral, superiores aos pagos no setor privado. 


\section{Base de dados e metodologia de trabalho}

\subsection{Base de dados}

São utilizados os dados da Pesquisa Nacional por Amostra de Domicílios (PNAD), realizada pelo IBGE, referentes aos anos de 1992, 1993, 1995 a 1999 e 2001 a 2005.

A PNAD é uma pesquisa baseada em uma amostra probabilística de domicílios que investiga diversas características socioeconômicas, como educação, trabalho e rendimento, além de características gerais da população (idade, sexo, cor, etc.).

Os dados captados pela PNAD apresentam uma série de limitações que restringem a análise dos resultados obtidos. Quatro dessas deficiências são particularmente relevantes no contexto deste trabalho:

(1) a subdeclaração dos rendimentos, sobretudo nos estratos mais altos de renda;

(2) a ausência de uma variável que possa ser usada para medir a riqueza de empregados do setor privado e de funcionários públicos;

(3) a omissão de vários tipos de renda real;

(4) a ausência de um quesito específico para captar rendimentos advindos de abonos salariais, participação nos lucros e resultados (PLR), comissões, prêmios e gratificações.

A tendência a subdeclarar o rendimento está presente em todas as pesquisas baseadas na declaração do entrevistado, em qualquer país. O grau de subdeclaração é tanto maior quanto maior é o rendimento do indivíduo e varia conforme a natureza do rendimento, sendo menor para os rendimentos do trabalho formal e os "oficializados", como pensões e aposentadorias, aumentando progressivamente quando se trata de rendimentos do trabalho informal e rendimentos de capital (Rocha, 2002). Além de resultar na subestimação da renda total do país, a subdeclaração dos rendimentos conduz à subestimação das diferenças regionais, dada a tendência de maior subdeclaração no caso dos rendimentos mais elevados. ${ }^{4}$

A ausência de uma variável que possa ser usada como medida da riqueza resulta na impossibilidade de se avaliar o efeito do capital físico sobre a renda do indivíduo. O resultado é a provável superestimação do efeito de outras variáveis

(4) Dividindo o rendimento anual per capita de cada unidade da federação, calculado com base nas declarações à PNAD de 1995, pelo PIB per capita estadual, Hoffmann (2001) verifica que o quociente obtido está próximo de 1 para os estados mais pobres, mas fica abaixo de 0,6 para os mais ricos. 
incluídas no modelo que estejam positivamente correlacionadas com a riqueza individual.

A omissão de vários tipos de renda real no cômputo do rendimento do trabalho é outra deficiência apresentada pela PNAD. É o caso, por exemplo, da parcela do salário recebida sob a forma de benefícios, ${ }^{5}$ tais como auxílio para moradia, alimentação, transporte, educação e saúde. Muitos desses benefícios são extensivos ao cônjuge e aos filhos do empregado. Em alguns casos, executivos recebem compensação ou bônus na forma de ações.

De acordo com Berndt (1991), as evidências empíricas sugerem que a proporção de benefícios não monetários na remuneração total dos empregados cresce à medida que crescem os salários e a porcentagem de empregados que recebem benefícios não monetários consideráveis aumenta à medida que aumenta o tamanho da firma.

Outro problema da PNAD na captação dos rendimentos do trabalho refere-se ao fato de que, embora a pesquisa pergunte ao entrevistado seu rendimento bruto, isto é, sem descontar os pagamentos referentes a fundos de previdência e imposto de renda, é pouco provável que o declarante assim o faça, estando mais inclinado a fornecer o valor líquido recebido.

Há que se notar, por fim, que a PNAD não incorpora ao rendimento mensal do trabalho os valores advindos de décimo terceiro salário (décimo quarto, décimo quinto, etc.), abonos, participação nos lucros e resultados (PLR), comissões, prêmios e gratificações. A pesquisa busca eliminar tais componentes, que julga atípicos, do rendimento do trabalho, haja vista o fato de perguntar ao entrevistado o valor do rendimento mensal "normalmente" auferido.

Abonos, PLR, comissões, etc. constituem, não obstante, componentes importantes da renda de empregados de determinadas atividades do setor terciário. No ramo imobiliário, no comércio e no mercado financeiro, por exemplo, as comissões vinculadas ao volume de negócios efetuado podem facilmente superar o piso salarial. Sua não captação, portanto, resulta na subestimação da renda dessas categorias de trabalhadores.

No setor público, por seu turno, é comum a ocorrência de gratificações vinculadas ao desempenho e ao tempo de serviço. Tal parcela do rendimento, no entanto, tende a ser imputada no valor do rendimento do trabalho, quando o trabalhador responde à pesquisa domiciliar, uma vez que ela é incorporada ao vencimento básico pelo próprio empregador - o Estado, no caso.

(5) De acordo com as "Notas técnicas" da publicação da PNAD 2004, "a parcela recebida em benefícios (moradia, alimentação, roupas, vales-refeição, alimentação ou transporte, etc.) não foi incluída no cômputo do rendimento do trabalho. (...) Os empregados (...) que recebiam apenas alimentação, roupas, medicamentos, etc. (benefícios), à guisa de rendimento de trabalho, foram incluídos no grupo 'sem rendimento de trabalho'”. 
Portanto, os dados sobre rendimento extraídos da PNAD e utilizados em estudos empíricos sobre determinação de renda podem não captar com precisão o diferencial total de salários entre trabalhadores. No caso de funcionários públicos e empregados do setor privado com carteira assinada, é possível que este diferencial seja superestimado. Entretanto, isto não invalida a análise aqui realizada, pois esta não tem como objetivo determinar um valor absoluto para o hiato salarial entre estas duas categorias, mas analisar a evolução do mesmo entre 1992 e 2005 período durante o qual os critérios de captação dos rendimentos do trabalho pela PNAD não se modificaram.

Cabe lembrar que uma diferença importante entre remunerações de funcionários públicos e empregados do setor privado ocorre após a aposentadoria, especialmente para aqueles que recebem salários relativamente elevados, devido ao fato de que a Constituição do país estabelecia, até 2003, o direito dos funcionários públicos receberem aposentadoria integral. Se, em lugar do salário mensal de pessoas ocupadas, fosse utilizada alguma medida da renda vitalícia das pessoas, certamente observaríamos uma diferença de renda maior a favor dos funcionários públicos.

\subsection{Metodologia de trabalho}

O presente trabalho considerou o universo de indivíduos ocupados com mais de 10 anos de idade. O conceito de ocupação utilizado, definido pelo IBGE, classifica como ocupadas as pessoas que tinham trabalho durante toda ou parte da semana de referência da pesquisa, incluindo os indivíduos que não exerceram o trabalho remunerado que tinham na semana de referência por motivo de férias, licença, greve, etc.

Foram constituídos dois grupos de análise, com o objetivo de estudar o contraste público-privado no mercado formal de trabalho.

O primeiro grupo é formado pelos indivíduos cuja posição na ocupação no trabalho principal, na semana de referência da PNAD, é "funcionário público estatutário". ${ }^{\circ}$ A este grupo pertencem todos os empregados federais, estaduais, municipais e de autarquias que são regidos pelo Estatuto dos Funcionários Públicos. Este trabalho não compreende, portanto, os funcionários públicos contratados sob as normas da Consolidação das Leis de Trabalho (CLT).

A Emenda Constitucional 19 de 1998 abriu brechas para a contratação de empregados não estatutários e sem carteira assinada no setor público. Não

(6) Como o objetivo deste trabalho é examinar o contraste de rendimento entre empregados públicos e privados equivalentes, e não existem indivíduos ocupando posição correspondente à de militar no setor privado, este segmento não será considerado neste estudo. 
incluiremos, no entanto, esses trabalhadores em nosso grupo de empregados do setor público, pois isso dificultaria a comparação dos dados anteriores a 1998 com aqueles posteriores a esse ano. Por conseguinte, tampouco foram considerados os empregados sem carteira assinada na categoria de empregados do setor privado (a seguir).

O outro grupo analisado consiste nos indivíduos que se declararam empregados com carteira em empreendimento do setor privado. Este grupo será doravante denominado "empregado do setor privado cca" - a sigla "cca" significando "com carteira assinada". Não foram acrescidas a este grupo as categorias de empregadores, trabalhadores por conta própria e trabalhadores domésticos, pois, além de o objetivo do trabalho ser estudar o diferencial de rendimentos entre empregados, estas são categorias à parte, que não possuem equivalentes no setor público.

Para ambos os grupos, a amostra sofreu uma série de exclusões. A mais importante delas consistiu na eliminação dos indivíduos pertencentes a ramos de atividade - no trabalho principal na semana de referência - ligados à agricultura e à indústria. Embora esta delimitação da amostra implique perda de comparabilidade em relação a outros estudos na área, ela foi julgada necessária porque foi encontrado um número muito pequeno de funcionários públicos estatutários ligados a ramos de atividade primários ou secundários, para todos os anos. $^{7}$

Visando à comparabilidade com os resultados dos anos anteriores, as informações referentes a 2004 e 2005 representam a cobertura geográfica da pesquisa existente até 2003, ou seja, sem incluir a área rural de Rondônia, Acre, Amazonas, Roraima, Pará e Amapá.

As equações de rendimento foram ajustadas separadamente para cada grupo segundo o método dos mínimos quadrados. Estabeleceu-se como variável

(7) Ao ajustar as equações de rendimento, estabeleceu-se como variável dependente o logaritmo do rendimento de todos os trabalhos, que só é definido para rendimentos positivos. Por este motivo, foram considerados apenas os indivíduos com valor positivo para aquele rendimento. Ademais, como é necessário dispor de informações válidas para todas as variáveis utilizadas como variáveis explanatórias na equação de rendimentos, foram excluídos da amostra os indivíduos de cor e idade ignorada, os de escolaridade não determinada ou sem declaração, os que não declararam o número de horas trabalhadas por semana em todos os trabalhos e ainda aqueles que, em relação ao ramo de atividade, declararam pertencer a outras atividades além daquelas constantes no formulário de entrevista, não souberam responder a este quesito ou cuja resposta foi mal definida. Finalmente, optou-se por excluir as pessoas que declararam número de horas trabalhadas habitualmente em todos os trabalhos superior a 108 horas por semana. O objetivo de tal procedimento é eliminar eventuais erros na captação dos dados pela PNAD, uma vez que julgamos improvável que um indivíduo possa trabalhar mais que 108 horas por semana. Ainda que um tanto arbitrária, tal exclusão não deve afetar a validade dos resultados, pois a amostra utilizada é muito grande. 
dependente o logaritmo neperiano do rendimento mensal de todos os trabalhos. ${ }^{8}$ Os valores de rendimento são expressos em reais de $1^{\underline{0}}$ de outubro de 2003 . O deflator utilizado para atualizar os valores anteriores e posteriores a esta data foi obtido por meio do procedimento proposto por Corseuil e Foguel (2002), com base no Índice Nacional de Preços ao Consumidor (INPC) Restrito, do IBGE. ${ }^{9}$ Para a construção da equação de rendimentos, procurou-se o conjunto de variáveis independentes que melhor explicasse o valor do logaritmo do rendimento de todos os trabalhos, de 1992 a 2005, para funcionários públicos estatutários e empregados do setor privado com carteira assinada. As variáveis incluídas devem captar o efeito do treinamento e da experiência das pessoas (idade e escolaridade), as discriminações e segmentações do mercado de trabalho (cor, sexo) e as diferenças regionais.

O modelo geral de regressão utilizado foi

$$
Y_{j}=\alpha+\sum_{i} \beta_{i} X_{i j}+u_{j}
$$

onde $\alpha$ e $\beta_{i}$ são parâmetros e $u_{j}$ são erros aleatórios heterocedásticos com as propriedades usuais. Por se tratar de um modelo com heterocedasticia, devemos ajustar as equações de rendimentos utilizando o método dos mínimos quadrados ponderados, usando o peso ou fator de expansão associado a cada pessoa da amostra, fornecido pelo IBGE, como fator de ponderação. ${ }^{10}$

As variáveis explanatórias usadas, listadas a seguir, são, em grande parte, variáveis binárias que assumem o valor 1 se o indivíduo pertence a determinado grupo, ou 0 , caso não pertença.

a) uma variável binária para sexo $\left(X_{1 j}\right)$, que assume valor 1 para mulheres;

(8) A escolha do logaritmo do rendimento no lugar do próprio rendimento, como variável dependente, deve-se ao fato de a distribuição do rendimento ser extremamente assimétrica, ao passo que o logaritmo do rendimento apresenta uma distribuição próxima da normal.

(9) Os ajustes propostos por Corseuil e Foguel (2002) ao INPC consistem na modificação da data de referência do índice e na alteração do valor referente a julho de 1994. A data de referência do INPC foi antecipada do dia 15 para o primeiro dia de cada mês, sob a justificativa de ser nesta data que os salários principal fonte de renda declarada em pesquisas domiciliares - são pagos e os dividendos são distribuídos. Além disso, os autores incorporaram um percentual adicional de 22,25\% à inflação reportada pelo INPC em julho de 1994, por entenderem que a variação de preços em URV (aferida pelo INPC) foi menor que a observada em cruzeiro real.

(10) Para as PNAD de 1992 a 1996 utilizamos os fatores de expansão divulgados na PNAD de 1997, os quais foram corrigidos com base na contagem populacional de 1996. No caso da PNAD de 1999, os cálculos foram feitos considerando os pesos corrigidos com base nos dados do Censo 2000, divulgados junto com a PNAD de 2001. Finalmente, para as PNAD de 2001 a 2003 utilizamos os fatores de expansão calculados com base na nova metodologia de projeção da população adotada pelo IBGE (denominada Revisão 2004), que foram divulgados em CD-ROM em outubro de 2004, em substituição ao CD-ROM da PNAD de 2003 divulgado em setembro de 2004 . 
b) a idade declarada pela pessoa, medida em dezenas de anos para evitar que os coeficientes sejam muito pequenos $\left(X_{2 j}\right)$;

c) o quadrado da idade da pessoa medida em dezenas de anos $\left(X_{3 j}\right)$, pois a influência da idade sobre o logaritmo do rendimento $\left(Y_{j}\right)$ não é linear, sendo que, a partir de certa idade, tende a ocorrer queda da produtividade do trabalho;

Se os parâmetros para a idade e idade ao quadrado forem indicados por $\beta_{1}$ e $\beta_{2}$, respectivamente, deve-se ter $\beta_{1}>0$ e $\beta_{2}<0$ e, então, o valor esperado de $Y_{j}$ será máximo quando a idade da pessoa, medida em dezenas de anos, for igual a $-\beta_{1} /\left(2 \beta_{2}\right)$.

d) quatro variáveis binárias $\left(X_{4 j}, X_{5 j}, X_{6 j}\right.$ e $\left.X_{7 j}\right)$ para distinguir indivíduos brancos (tomados como base), indígenas, pretos, amarelos e pardos;

e) o logaritmo neperiano da soma do número de horas semanais de trabalho na atividade principal, na secundária e em outras atividades ${ }^{11}\left(X_{8 j}\right)$; o coeficiente dessa variável $\left(\beta_{8}\right)$ é a elasticidade do rendimento em relação ao tempo semanal de trabalho;

f) cinco variáveis binárias $\left(X_{9 j}, \quad X_{10 j}, \quad X_{11 j}, \quad X_{12 j}\right.$ e $\left.X_{13 j}\right)$ para distinguir seis grandes regiões: Nordeste (tomado como base), Norte, Sudeste (excluindo o Estado de São Paulo), o Estado de São Paulo, Sul e Centro-Oeste;

g) uma variável binária $\left(X_{14 j}\right)$ para diferenciar a condição do indivíduo na unidade domiciliar, que assume valor 1 para a pessoa de referência no domicílio e valor 0 para cônjuge, filhos e outros;

h) duas variáveis binárias $\left(X_{15 j}\right.$ e $\left.X_{16 j}\right)$ para caracterizar a localização do domicílio: domicílio situado em região metropolitana (categoria tomada como base), domicílio situado em área urbana não metropolitana e domicílio situado em área rural não metropolitana;

i) escolaridade $\left(X_{17 j}\right)$, variando de 0 (no caso de pessoa sem instrução ou com menos de 1 ano de estudo) a 14 (no caso de pessoa com 14 anos de estudo) e assumindo valor 17 para pessoas com 15 ou mais anos de estudo;

(11) A decisão de incorporar o rendimento de atividades secundárias ao salário recebido pelo trabalho principal deriva da constatada importância destas fontes adicionais de renda para os trabalhadores do setor terciário, notadamente para os funcionários públicos. Em 2003, por exemplo, 3,67\% dos empregados do setor privado cca possuíam mais de um trabalho na semana de referência da PNAD; entre os funcionários públicos, esta proporção era de $12,49 \%$. 
j) uma variável $\left(X_{18 j}\right)$ destinada a captar o aumento da taxa de retorno da escolaridade a partir dos 9 anos de estudo, tal que

$$
X_{18 j}=Z_{j}\left(X_{17 j}-9\right)
$$

onde $Z_{j}$ é uma variável binária que assume valor 0 para $X_{17 j} \leq 9$ e valor 1 para $X_{17 j}>9$.

O modelo da regressão passou a ser

$$
Y_{j}=\alpha+\sum_{i=1}^{16} \beta_{i} X_{i j}+\beta_{17} X_{17 j}+\beta_{18} Z_{j}\left(X_{17 j}-9\right)+u_{j}
$$

onde $\beta_{17}$ é o efeito de cada ano adicional de escolaridade até os 9 anos de escolaridade e $\beta_{17}+\beta_{18}$ o efeito a partir deste ponto. Este modelo corresponde a pressupor que a relação entre $E\left(Y_{j}\right)$ e a escolaridade $X_{17 j}$ tem a forma de uma poligonal com vértice no ponto de abscissa $X_{17 j}=9 .^{12}$

\subsection{A decomposição de Blinder-Oaxaca}

A abordagem de Blinder-Oaxaca foi originalmente desenvolvida com o intuito de mensurar os efeitos sobre os salários da discriminação por gênero e por cor. Trata-se de um método para decompor as variações de rendimento entre dois grupos de trabalhadores na parcela referente a diferenças de atributos produtivos (escolaridade, experiência, etc.) entre os indivíduos de cada grupo e na parcela referente a efeitos de discriminação contra os indivíduos de um dos grupos. Admite-se que, na ausência de discriminação, os efeitos estimados sobre o rendimento dos atributos dos trabalhadores são idênticos para os dois grupos. A discriminação é revelada por diferenças nos coeficientes estimados (tanto do intercepto quanto da declividade da função) das equações de rendimento.

Zucchi e Hoffmann (2004) utilizam a metodologia de Blinder-Oaxaca para quantificar o efeito da discriminação racial sofrida por negros (pretos e pardos), no Brasil, em 2001. Leme e Wajnman (2000) associam esta metodologia à análise de coortes populacionais, a fim de determinar as causas da tendência à redução do hiato salarial por sexo no Brasil nos últimos vinte anos.

(12) O uso de uma função em forma de poligonal para captar o aumento da taxa de retorno à educação a partir de certo nível de escolaridade aparece nos trabalhos de Ney e Hoffmann (2003), Zucchi e Hoffmann (2004) e é mais amplamente discutido em Hoffmann e Ney (2004). Ao estimar e testar a significância estatística do fenômeno no Brasil, esses trabalhos usaram dados da PNAD. Hoffmann e Simão (2005), por seu turno, estimaram e testaram este efeito em equações de rendimento estimadas com base nos dados do Censo Demográfico de 2000. 
Soares (2000) também utiliza a metodologia de Blinder-Oaxaca para identificar e quantificar os efeitos sobre os rendimentos da discriminação contra negros e contra mulheres no mercado de trabalho brasileiro. Sua contribuição consiste em estimar dois modelos distintos: o primeiro incluindo controles para nível educacional e idade (esta última servindo como medida aproximada da experiência profissional), mas sem controles para o tipo de inserção do indivíduo no mercado de trabalho; o segundo adicionando controles (na forma de variáveis binárias) para setor de atividade, região do país e tipo de inserção legal no mercado de trabalho (posse de carteira de trabalho e trabalho por conta-própria). Com isso, visa-se captar o diferencial de rendimentos associado exclusivamente à discriminação no momento de definição salarial, isolando as diferenças associadas ao tipo de inserção do indivíduo no mercado de trabalho.

$\mathrm{O}$ artigo de Campante et al. (2004) atém-se à questão da discriminação racial contra negros (pretos e pardos) no Brasil e propõe-se a avançar em questões que julga problemáticas no trabalho de Soares (2000). O autor considera pertinente incluir a variável escolaridade dos pais no modelo da equação de rendimentos, devido à importância do fator transmissão intergeracional de educação. Ademais, são incluídas variáveis binárias para regiões, pois se supõe que, dada a heterogeneidade do país, o perfil da discriminação no mercado de trabalho seja bastante diferente de uma região para outra. Para captar o efeito gerado por estas contribuições ao modelo de Soares (2000), o autor utiliza uma versão adaptada da metodologia de Blinder-Oaxaca, na qual, ao invés de transportar os parâmetros estimados todos de uma só vez para realizar a simulação contrafatual, separa as variáveis em blocos, ${ }^{13}$ de forma que cada conjunto de parâmetros estimados seja transportado de cada vez. Desta forma, é possível estimar quanto cada bloco ou grupo de parâmetros contribui para a discriminação salarial.

No presente trabalho, o contexto de aplicação da metodologia BlinderOaxaca é outro. Os grupos cujos rendimentos desejamos comparar diferem devido a fatores institucionais - pertencem a mercados de trabalhos regidos por regras distintas. Logo, a diferença salarial entre ambos não pode ser interpretada como discriminação. A decomposição de Blinder-Oaxaca, no entanto, pode ser aplicada a este caso para a compreensão da importância do componente institucional na geração do hiato de rendimento entre os grupos. Em outras palavras, ela pode ajudar a entender qual parcela da diferença de rendimento entre empregados públicos e privados é atribuível aos diferentes perfis produtivos de cada grupo e

(13) O autor estabelece os seguintes conjuntos de variáveis: 1ํㅡ - características individuais: variáveis educação, experiência (corresponde à idade do indivíduo menos a idade com que entrou no mercado de trabalho) e gênero; $2^{\underline{0}}$ - características do mercado de trabalho: variáveis "com ou sem carteira", "setor público ou privado" e setor de atividade; $3^{\text {o }}$ - características regionais: variável região e "área metropolitana ou não metropolitana"; $4^{\circ}$ - escolaridade da mãe. 
em que medida esses diferenciais resultam dos distintos critérios de remuneração praticados em cada segmento.

A abordagem supõe, primeiramente, que sejam estimadas separadamente, segundo o método dos mínimos quadrados, as equações de rendimento para cada grupo. As equações são então consideradas nos pontos médios das variáveis do grupo A (funcionários públicos) e do grupo B (empregados em serviços no setor privado cca):

$$
\begin{array}{ll}
\bar{Y}_{A}=\hat{\alpha}_{A}+\sum_{i} \hat{\beta}_{i A} \bar{X}_{i A} & \text { para o grupo A e } \\
\bar{Y}_{B}=\hat{\alpha}_{B}+\sum_{i} \hat{\beta}_{i B} \bar{X}_{i B} & \text { para o grupo B. }
\end{array}
$$

Em seguida, subtrai-se uma equação da outra, a fim de obter uma expressão para a diferença das médias do logaritmo do rendimento entre os dois grupos

$$
\bar{Y}_{A}-\bar{Y}_{B}=\left(\hat{\alpha}_{A}-\hat{\alpha}_{B}\right)+\sum_{i} \hat{\beta}_{i A} \bar{X}_{i A}-\sum_{i} \hat{\beta}_{i B} \bar{X}_{i B}
$$

Somando e subtraindo o termo $\sum_{i} \hat{\beta}_{i A} \bar{X}_{i B}$ do segundo membro dessa equação e reescrevendo-a, obtém-se

$$
\bar{Y}_{A}-\bar{Y}_{B}=\left(\hat{\alpha}_{A}-\hat{\alpha}_{B}\right)+\sum_{i} \hat{\beta}_{i A}\left(\bar{X}_{i A}-\bar{X}_{i B}\right)+\sum_{i} \bar{X}_{i B}\left(\hat{\beta}_{i A}-\hat{\beta}_{i B}\right)
$$

Portanto, a diferença entre a remuneração dos indivíduos do grupo A e do B pode ser decomposta mediante a seguinte expressão

$$
\begin{aligned}
& \bar{Y}_{A}-\bar{Y}_{B}=D+E \quad \text { onde } \\
& D=\left(\hat{\alpha}_{A}-\hat{\alpha}_{B}\right)+\sum_{i} \bar{X}_{i B}\left(\hat{\beta}_{i A}-\hat{\beta}_{i B}\right) \quad \mathrm{e} \\
& E=\sum_{i} \hat{\beta}_{i A}\left(\bar{X}_{i A}-\bar{X}_{i B}\right)
\end{aligned}
$$

O termo $E$ - que denominaremos efeito de médias - representa a parcela da diferença de rendimentos que é explicada pelas diferenças nas médias das características produtivas da mão-de-obra.

O termo $D$ - que chamaremos efeito de parâmetros - quantifica o diferencial de rendimento que decorre da diferença nos efeitos que as características produtivas têm sobre a remuneração; esse termo inclui a diferença de nível $\left(\hat{\alpha}_{A}-\hat{\alpha}_{B}\right)$ e $\sum_{i} \bar{X}_{i B}\left(\hat{\beta}_{i A}-\hat{\beta}_{i B}\right)$, que é a parte da diferença de salários 
que se deve à valorização desigual de um mesmo atributo para os indivíduos do grupo A e do grupo B.

Nesta decomposição, as diferenças das médias das características dos trabalhadores são multiplicadas pelos coeficientes estimados do grupo A, ou seja, elas são ponderadas pelo valor que se dá a essas características para o grupo A. Já as diferenças nas estimativas dos coeficientes são ponderadas pelas médias das características dos indivíduos do grupo B.

Uma alternativa igualmente plausível consiste em somar e subtrair o termo $\sum_{i} \hat{\beta}_{i B} \bar{X}_{i A}$ do segundo membro da equação (6), obtendo-se

$$
\bar{Y}_{A}-\bar{Y}_{B}=\left(\hat{\alpha}_{A}-\hat{\alpha}_{B}\right)+\sum_{i} \bar{X}_{i A}\left(\hat{\beta}_{i A}-\hat{\beta}_{i B}\right)+\sum_{i} \hat{\beta}_{i B}\left(\bar{X}_{i A}-\bar{X}_{i B}\right)
$$

ou ainda

$$
\begin{aligned}
& \bar{Y}_{A}-\bar{Y}_{B}=D^{\prime}+E^{\prime} \quad \text { onde } \\
& D^{\prime}=\left(\hat{\alpha}_{A}-\hat{\alpha}_{B}\right)+\sum_{i} \bar{X}_{i A}\left(\hat{\beta}_{i A}-\hat{\beta}_{i B}\right) \quad \mathrm{e} \\
& E^{\prime}=\sum_{i} \hat{\beta}_{i B}\left(\bar{X}_{i A}-\bar{X}_{i B}\right)
\end{aligned}
$$

Neste caso, as diferenças das médias de características são ponderadas pelos coeficientes estimados dos trabalhadores do grupo B e as diferenças dos coeficientes são ponderadas pelas características médias dos trabalhadores do grupo A.

A escolha entre a equação (7) e a (11) envolve a decisão sobre quais pesos empregar. No presente artigo, optamos por apresentar os resultados obtidos com a equação (11). Aqueles obtidos com a equação (7) podem ser consultados em Vaz (2005), sendo que conduzem às mesmas conclusões aqui expostas.

No caso da escolaridade, o efeito de médias é dado por $\hat{\beta}_{17 B}\left(\bar{X}_{17 A}-\bar{X}_{17 B}\right)+\hat{\beta}_{18 B}\left(\bar{X}_{18 A}-\bar{X}_{18 B}\right)$ e o de parâmetros por $\bar{X}_{17 A}\left(\hat{\beta}_{17 A}-\hat{\beta}_{17 B}\right)+\bar{X}_{18 A}\left(\hat{\beta}_{18 A}-\hat{\beta}_{18 B}\right)$.

A contribuição percentual do fator escolaridade para o efeito de médias da diferença de logaritmos de rendimentos de funcionários públicos e empregados do setor privado cca é dada por

$$
\frac{\hat{\beta}_{17 B}\left(\bar{X}_{17 A}-\bar{X}_{17 B}\right)+\hat{\beta}_{18 B}\left(\bar{X}_{18 A}-\bar{X}_{18 B}\right)}{\sum_{i=1}^{18} \hat{\beta}_{i B}\left(\bar{X}_{i A}-\bar{X}_{i B}\right)} 100
$$


Já a contribuição percentual do fator escolaridade no efeito de parâmetros é calculada mediante a expressão

$$
\frac{\bar{X}_{17 A}\left(\hat{\beta}_{17 A}-\hat{\beta}_{17 B}\right)+\bar{X}_{18 A}\left(\hat{\beta}_{18 A}-\hat{\beta}_{18 B}\right)}{\left(\hat{\alpha}_{A}-\hat{\alpha}_{B}\right)+\sum_{i=1}^{18} \bar{X}_{i A}\left(\hat{\beta}_{i A}-\hat{\beta}_{i B}\right)} 100
$$

Por fim, a participação da escolaridade na diferença total de logaritmos de rendimentos entre os dois grupos é dada pela soma do efeito de médias ao efeito de parâmetros, dividida pela diferença total entre os logaritmos dos rendimentos de cada grupo. Após simplificação, essa expressão torna-se igual a

$$
\left(\frac{\hat{\beta}_{17 A} \bar{X}_{17 A}-\hat{\beta}_{17 B} \bar{X}_{17 B}+\hat{\beta}_{18 A} \bar{X}_{18 A}-\hat{\beta}_{18 B} \bar{X}_{18 B}}{\bar{Y}_{A}-\bar{Y}_{B}}\right) 100
$$

\section{Resultados e discussão}

A evolução dos valores reais dos rendimentos médio e mediano de todos os trabalhos, para funcionários públicos estatutários, pode ser examinada na Tabela 1. Destaca-se o forte crescimento do rendimento médio entre 1993 e 1995 $(25,06 \%)$. Entre 1995 e 1998, o valor oscilou em torno de $\mathrm{R} \$ 1.298,42$, para sofrer uma queda de cerca de 5\% em 1999, seguida de recuperação parcial em 2001 (4\%). Entre 2001 e 2003, o rendimento médio sofreu uma contração de aproximadamente 10\%. Em 2004 e, sobretudo, em 2005 sofreu recuperação, embora não tenha retornado ao patamar observado em 2001.

O rendimento médio de todos os trabalhos de empregados do setor privado cca situou-se, no período considerado, em torno de $\mathrm{R} \$ 771$ (Tabela 1), o que representa $62,6 \%$ do rendimento médio de funcionários públicos estatutários. Entre 1992 e 1993, o rendimento médio deste grupo permaneceu praticamente estagnado, ao passo que, para funcionários públicos, cresceu 7,61\%. Ademais, o crescimento da renda média entre 1993 e 1995 foi sensivelmente inferior ao observado para funcionários públicos (18,38\% contra 25,06\%). Finalmente, é preciso destacar a contração de 6,36\% do rendimento médio em 1999, em relação a 1998. Ao contrário dos funcionários públicos, os empregados do setor privado cca não verificaram qualquer recuperação de seu rendimento médio em 2001, e voltaram a enfrentar nova queda em 2002 (de 4,46\%) e em 2003 (8,31\%). A recuperação ocorrida no biênio 2004-2005 foi menor que aquela observada entre os funcionários públicos e insuficiente para elevar o rendimento médio ao valor observado em 1998. Por conseguinte, enquanto a renda média de funcionários 
públicos, de 1992 a 2005, cresceu 34,9\%, a de empregados do setor privado cresceu apenas $4,18 \%$. A diferença de rendimento entre funcionários públicos e empregados do setor privado cca ampliou-se, assim, de forma não desprezível no período considerado, o que se evidencia pelo aumento da relação A/B (rendimento médio de funcionário público sobre rendimento médio de empregado do setor privado cca) de 1,37 para 1,78 entre 1992 e 2005.

Tabela 1

Média e mediana do rendimento de todos os trabalhos, para funcionários públicos e empregados do setor privado cca, em $\mathrm{R} \$$ de $01 / 10 / 2003$

\begin{tabular}{l|c|c|c|c|c}
\hline \multirow{2}{*}{ Ano } & \multicolumn{2}{|c|}{ Funcionário público } & \multicolumn{2}{c}{ Empregado do setor privado } & \multicolumn{2}{c}{ A/B } \\
\cline { 2 - 5 } & Média (A) & Mediana & Média (B) & Mediana & \\
\hline 1992 & 952,81 & 640,13 & 694,02 & 457,24 & 1,37 \\
\hline 1993 & $1.025,33$ & 619,04 & 678,98 & 433,33 & 1,51 \\
\hline 1995 & $1.282,27$ & 758,89 & 803,76 & 531,22 & 1,60 \\
\hline 1996 & $1.268,12$ & 778,08 & 849,06 & 548,54 & 1,49 \\
\hline 1997 & $1.296,12$ & 808,84 & 853,05 & 566,19 & 1,52 \\
\hline 1999 & $1.347,19$ & 847,52 & 870,43 & 552,45 & 1,55 \\
\hline 2001 & $1.278,95$ & 811,02 & 815,03 & 530,85 & 1,57 \\
\hline 2002 & $1.330,14$ & 886,10 & 793,76 & 513,68 & 1,68 \\
\hline 2003 & $1.297,63$ & 817,80 & 758,35 & 467,31 & 1,71 \\
\hline Média do período & $1.231,77$ & 777,63 & 770,76 & 503,10 & 1,72 \\
\hline
\end{tabular}

Fonte: Elaboração dos autores.

De fato, observando as médias dos logaritmos do rendimento de todos os trabalhos para as duas categorias, verifica-se que, em 1992, os empregados do setor privado cca auferiam um rendimento cerca de $20 \%$ inferior ao rendimento dos funcionários públicos. Em 2005, esta diferença havia se ampliado para aproximadamente $36 \%$, como mostra o Gráfico $1 .^{14}$

(14) Outra forma de verificar a ampliação deste hiato salarial é tomar as medidas de desigualdade $T$ e $L$ de Theil, calculadas para funcionários públicos e empregados do setor privado cca somados, e decompô-las na parcela referente à desigualdade entre os dois grupos e na parcela correspondente à desigualdade dentro de ambos os grupos (ver Hoffmann, 1998). Realizando este procedimento, observou-se que a parcela dos índices $T$ e $L$ de Theil referente à desigualdade entre os grupos aumentou entre 1992 e 2005 . No caso do índice $T$ de Theil, este valor elevou-se de $2,71 \%$ para $9,13 \%$. No caso do $L$ de Theil, que é uma medida mais sensível a alterações na desigualdade entre os indivíduos de baixa renda, a parcela da desigualdade entre os grupos passou de 3,09\% em 1992 para 10,81\% em 2005. Tal aumento da participação do componente entre grupos no valor total das medidas de desigualdade de Theil condiz com o constatado crescimento do hiato salarial entre funcionários públicos e empregados do setor privado cca. 
Gráfico 1

Diferença entre médias geométricas de rendimentos de funcionários públicos e empregados do setor privado cca

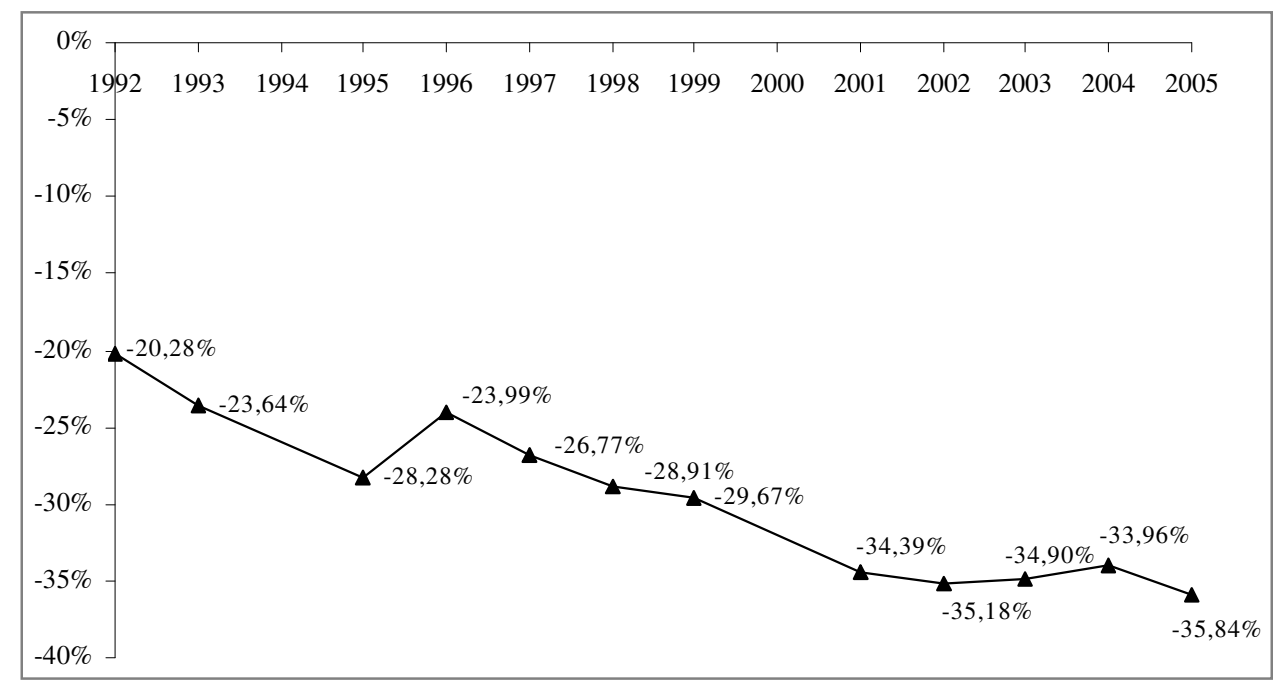

Fonte: Elaboração dos autores.

Na tabela a seguir são apresentadas as medidas de desigualdade de Gini e de Theil, calculadas separadamente para cada categoria, de 1992 a 2005.

Tabela 2

Principais medidas de desigualdade da distribuição do rendimento de todos os trabalhos de funcionários públicos e empregados do setor privado cca ocupados em serviços, no Brasil, de 1992 a 2005

\begin{tabular}{l|c|c|c|c|c|c}
\hline \multirow{2}{*}{ Ano } & \multicolumn{3}{|c|}{ Funcionários públicos } & \multicolumn{3}{c}{ Empregados do setor privado cca } \\
\cline { 2 - 7 } & $G^{(1)}$ & $T^{(2)}$ & $L^{(3)}$ & $G^{(1)}$ & $T^{(2)}$ & $L^{(3)}$ \\
\hline 1992 & 0,479 & 0,425 & 0,413 & 0,442 & 0,407 & 0,322 \\
\hline 1993 & 0,520 & 0,541 & 0,485 & 0,455 & 0,430 & 0,342 \\
\hline 1995 & 0,518 & 0,504 & 0,482 & 0,457 & 0,433 & 0,348 \\
\hline 1996 & 0,515 & 0,492 & 0,479 & 0,460 & 0,428 & 0,352 \\
\hline 1997 & 0,501 & 0,462 & 0,446 & 0,452 & 0,417 & 0,339 \\
\hline 1998 & 0,500 & 0,462 & 0,438 & 0,455 & 0,431 & 0,343 \\
\hline 1999 & 0,494 & 0,448 & 0,426 & 0,446 & 0,410 & 0,328 \\
\hline 2001 & 0,489 & 0,443 & 0,414 & 0,441 & 0,415 & 0,319 \\
\hline 2002 & 0,488 & 0,436 & 0,410 & 0,433 & 0,396 & 0,306 \\
\hline 2003 & 0,484 & 0,434 & 0,399 & 0,418 & 0,370 & 0,285 \\
\hline 2004 & 0,490 & 0,443 & 0,407 & 0,419 & 0,380 & 0,287 \\
\hline 2005 & 0,486 & 0,439 & 0,399 & 0,405 & 0,352 & 0,267 \\
\hline
\end{tabular}

(1) Índice de Gini; (2) Índice $T$ de Theil; (3) Índice $L$ de Theil.

Fonte: Elaboração dos autores. 
Observa-se que as medidas de desigualdade da distribuição do rendimento são sempre maiores para funcionários públicos. Este resultado, em princípio, não deve ser considerado problemático, pois o papel do emprego público não é melhorar a distribuição de renda. Ademais, certa amplitude salarial é necessária para estimular a progressão na carreira pública. Por fim, é possível que a subdeclaração das rendas mais altas seja maior entre os funcionários do setor privado, o que resultaria na subestimação das medidas de desigualdade de rendimento desta categoria de trabalhadores.

Entre 1992 e 1993, tanto o índice de Gini como as medidas $T$ e $L$ de Theil calculadas para funcionários públicos aumentaram significativamente: $8,46 \%$ no caso do índice de Gini, 27,27\% para o $T$ de Theil e 17,41\% para o $L$ de Theil. Entre 1995 e 2003, as três medidas diminuíram lentamente — à exceção do $T$ de Theil de 1997 para 1998 —, retornando a um nível próximo ao verificado em 1992. Em 2004 apresentaram pequeno aumento, praticamente contrabalançado pela diminuição observada em 2005.

No biênio 1992-1993, as medidas de desigualdade calculadas para empregados do setor privado cca também sofreram aumento, mas de forma muito menos intensa que a verificada para funcionários públicos: 3,02\%, 5,59\% e 6,10\% para o Gini, o $T$ de Theil e o $L$ de Theil, respectivamente. Em contrapartida, de 1993 a 2003, ao mesmo tempo em que se verificou oscilação dessas medidas, ocorreram quedas expressivas, que levaram à diminuição dos índices de Gini, $T$ de Theil e $L$ de Theil de, respectivamente, $8,31 \%, 14,00 \%$ e 16,75\%. Por conseguinte, os valores dessas três medidas observados em 2003 são os menores de toda a série. De 2002 para 2003, em particular, o $L$ de Theil caiu de 0,306 para 0,285. Trata-se de uma redução pequena, mas não desprezível, uma vez que se trata de um intervalo de apenas 1 ano, no qual o rendimento médio passou de $\mathrm{R} \$ 758,35$ para $\mathrm{R} \$$ 695,35. Seguindo o comportamento observado para funcionários públicos, em 2004 observou-se pequena elevação das três medidas de desigualdade, mais que compensada pela diminuição observada em 2005, que foi mais importante para as medidas de desigualdade de Theil.

\subsection{Causas do diferencial de rendimentos entre funcionários públicos e empregados do setor privado cca}

\subsubsection{Atributos individuais}

A vantagem salarial de funcionários públicos em relação a empregados do setor privado cca reflete, em certa medida, a diferença no perfil dos indivíduos que compõem cada um destes grupos. A Tabela 3 mostra a distribuição de funcionários públicos e empregados do setor privado cca segundo categorias de 
diversas variáveis, em 2005. A Tabela 4 mostra, para o mesmo ano, as idades, escolaridades e logaritmos do número de horas semanais de trabalho médios dos dois grupos.

Tabela 3

Distribuição dos funcionários públicos e dos empregados do setor privado cca, no Brasil, em 2005, em categorias de diversas variáveis (\%)

\begin{tabular}{|c|c|c|}
\hline Variável & Funcionário público & $\begin{array}{l}\text { Empregado do setor privado } \\
\text { cca }\end{array}$ \\
\hline \multicolumn{3}{|l|}{ Sexo } \\
\hline Masculino & 39,44 & 55,86 \\
\hline Feminino & 60,56 & 44,14 \\
\hline \multicolumn{3}{|l|}{ Cor } \\
\hline Branco & 57,47 & 59,94 \\
\hline Indígena & 0,18 & 0,19 \\
\hline Preto & 6,77 & 6,67 \\
\hline Amarelo & 0,53 & 0,51 \\
\hline Pardo & 35,04 & 32,68 \\
\hline \multicolumn{3}{|l|}{ Localização do domicílio } \\
\hline Região metropolitana & 30,58 & 42,59 \\
\hline Urbana não metropolitana & 64,30 & 55,33 \\
\hline Rural não metropolitana & 5,12 & 2,08 \\
\hline \multicolumn{3}{|l|}{ Condição na família } \\
\hline Pessoa de referência & 51,33 & 45,95 \\
\hline Demais & 48,67 & 54,05 \\
\hline \multicolumn{3}{|l|}{ Região } \\
\hline Nordeste & 24,48 & 14,76 \\
\hline Norte & 8,56 & 4,47 \\
\hline $\mathrm{MG}+\mathrm{ES}+\mathrm{RJ}$ & 22,24 & 25,21 \\
\hline SP & 18,70 & 29,47 \\
\hline Sul & 14,94 & 18,06 \\
\hline Centro-Oeste & 11,09 & 8,03 \\
\hline
\end{tabular}

Fonte: Elaboração dos autores.

Tabela 4

Média das variáveis idade, anos de estudo e logaritmo do $\mathrm{n}^{0}$ de horas semanais de trabalho para funcionários públicos e empregados do setor privado cca, no Brasil, em 2005

\begin{tabular}{l|c|c}
\hline Variável & Funcionário público & Empregado do setor privado cca \\
\hline Idade & 41,63 & 32,49 \\
\hline Anos de estudo & 11,97 & 9,79 \\
\hline $\begin{array}{l}\text { Logaritmo neperiano do número de } \\
\text { horas semanais de trabalho }\end{array}$ & 3,6327 & 3,7886 \\
\hline
\end{tabular}

Fonte: Elaboração dos autores. 
A idade média de funcionários públicos em 2005 era de aproximadamente 41,6 anos, contra cerca de 32,5 para empregados do setor privado cca. Em relação à escolaridade, os funcionários públicos apresentavam, em média, 11,97 anos de estudo, contra 9,79 anos para empregados do setor privado cca. Assim, as diferenças de idade e de escolaridade explicam ao menos em parte o hiato salarial a favor de funcionários públicos, uma vez que é natural atribuir maiores rendimentos a indivíduos com maior nível de escolaridade e experiência.

É importante observar, no entanto, que na carreira pública o salário é reajustado à medida que o indivíduo acumula anos de serviço, ${ }^{15}$ mesmo que seus atributos pessoais permaneçam os mesmos e ele continue desempenhando a mesma função, da mesma forma como sempre o fez, ou seja, com a mesma produtividade. Assim, a prerrogativa da estabilidade ${ }^{16}$ existente neste segmento assegura certa progressão salarial a todos os funcionários. No setor privado, onde a rotatividade dos trabalhadores é muito maior, a progressão salarial depende necessariamente de incrementos na qualificação pessoal e/ou do acúmulo de experiência profissional no desempenho da função, o qual não está associado ao simples passar do tempo, devendo se traduzir em ganhos de produtividade. ${ }^{17}$ Destarte, na carreira pública a maior idade é necessariamente sinônimo de maior salário, o mesmo não ocorrendo no setor privado.

Além de serem, em média, mais jovens e menos qualificados, os empregados do setor privado cca não são, em sua maioria, a pessoa de referência (isto é, o chefe) da família. Este perfil reflete, em certa medida, o ingresso precoce de jovens no setor de serviços privado, em atividades pouco qualificadas, como office-boy, manobrista, vendedor, porteiro, vigia, garçom, manicuro, etc. $\mathrm{Na}$ carreira pública, a existência de requisitos mínimos de idade e formação torna restrito o ingresso de jovens pouco qualificados.

Os funcionários públicos trabalham, em média, 39,7 horas por semana. A jornada semanal dos empregados do setor privado é de, em média, 45,5 horas semanais, $14,75 \%$ maior, portanto.

Em relação à localização do domicílio, a maior parte dos empregados do setor terciário, tanto do setor privado quanto do público, residem em áreas urbanas não metropolitanas. Entre os empregados do setor privado cca, 55,33\% residiam nestas áreas em 2005; entre os funcionários públicos esta proporção era ainda maior: $64,30 \%$.

(15) O Artigo 129 da Constituição do Estado de São Paulo, por exemplo, assegura aos servidores públicos estaduais o "adicional por tempo de serviço" (qüinquiênios e sexta parte aos 20 anos de exercício).

(16) O Artigo 41 da Constituição brasileira assegura o direito à estabilidade ao servidor que completar três anos de efetivo exercício em cargo obtido por concurso público.

(17) É claro que, na carreira pública, ganhos de produtividade também são premiados com maiores salários, bônus, gratificações, etc. 
No que tange à cor do indivíduo, percebemos que os dois grupos apresentam o mesmo perfil, ou seja, apresentam proporções de brancos, indígenas, pretos, amarelos e pardos muito semelhantes. Há predominância de trabalhadores brancos (cerca de 59\%), que são seguidos de pardos (em torno de 34\%) e de pretos (em torno de 7\%).

Em relação à distribuição geográfica dos indivíduos dos dois grupos, constata-se que os funcionários públicos estão espacialmente menos concentrados que os empregados do setor privado cca. É verdade que há uma forte proporção de funcionários públicos no Nordeste $(24,5 \%)$ e no eixo MG+ES+RJ $(22,2 \%)$, mas eles estão presentes em proporções não inferiores a $8 \%$ nas demais regiões e no estado de São Paulo, devido ao contingente mínimo de funcionários necessários para gerir os governos municipais e estaduais. Dentre os empregados do setor privado cca, mais da metade se encontra na região Sudeste, divididos entre SP $(29,5 \%)$ e MG+ES+RJ (25,2\%), sendo reduzidas as proporções encontradas no Centro-Oeste (8\%) e Norte do país (4,5\%).

A proporção de mulheres observadas nos dois grupos, por outro lado, contribuiria para que o rendimento médio no setor privado cca fosse maior do que o observado entre funcionários públicos. Isto porque as mulheres tendem a ganhar menos e elas predominam entre os funcionários públicos (eram quase $61 \% \mathrm{em}$ 2005), enquanto entre os empregados do setor privado cca elas são cerca de $44 \%$. Apesar disso, já vimos que o rendimento médio é maior para os funcionários públicos, o que revela que os fatores que levam funcionários públicos a auferirem maiores rendimentos que empregados do setor privado cca superam, com certa folga, o efeito negativo que a predominância de mulheres pode exercer sobre o rendimento deste grupo.

\subsubsection{Análise de regressão}

Ajustando separadamente equações de rendimento para cada grupo com base nos atributos pessoais considerados no item anterior e de acordo com o modelo de regressão descrito no item 2.2, constata-se que as variáveis explanatórias estão longe de explicar plenamente as variações do logaritmo do rendimento de funcionários públicos e de empregados do setor privado cca, pois o

coeficiente de determinação $\left(R^{2}\right)$ do modelo situa-se em torno de $50 \%$, para ambos os grupos, tanto em 2005 (Tabela 5) como em todos os outros anos da série.

A Tabela 5 apresenta os resultados das equações estimadas para 2005, considerando, alternativamente, funcionários públicos ou empregados do setor privado cca. 
Tabela 5

Estimativa da equação de rendimentos de funcionários públicos e empregados do setor privado cca, no Brasil, em 2005

\begin{tabular}{|c|c|c|}
\hline Variável & Funcionário público & Empregado do setor privado cca \\
\hline Constante & 2,9958 & 3,8728 \\
\hline Sexo & $-0,3329$ & $-0,2482$ \\
\hline Idade/10 & 0,4938 & 0,4930 \\
\hline$(\text { Idade } / 10)^{2}$ & $-0,0449$ & $-0,0460$ \\
\hline \multicolumn{3}{|l|}{ Cor } \\
\hline Indígena & 0,1584 & $-0,0373$ \\
\hline Preto & $-0,0903$ & $-0,1206$ \\
\hline Amarelo & 0,2301 & 0,1109 \\
\hline Pardo & $-0,0906$ & $-0,1014$ \\
\hline Escolaridade (E) & 0,0603 & 0,0279 \\
\hline$E^{*}=Z(E-9)$ & 0,0648 & 0,1029 \\
\hline Log $\mathrm{n}^{\mathrm{o}}$ horas trab./semana & 0,4962 & 0,2241 \\
\hline Condição na família & 0,1295 & 0,1491 \\
\hline \multicolumn{3}{|l|}{ Região } \\
\hline Norte & 0,1920 & 0,1420 \\
\hline $\mathrm{MG}+\mathrm{ES}+\mathrm{RJ}$ & 0,1051 & 0,1352 \\
\hline SP & 0,2183 & 0,3337 \\
\hline Sul & 0,1522 & 0,2446 \\
\hline Centro-Oeste & 0,3246 & 0,2534 \\
\hline \multicolumn{3}{|l|}{ Localização do domicílio } \\
\hline Urbana não metropolitana & $-0,2868$ & $-0,1080$ \\
\hline Rural não metropolitana & $-0,4113$ & $-0,1521$ \\
\hline$R^{2}(\mathrm{em} \%)$ & 52,39 & 45,62 \\
\hline Teste $F$ & 703,59 & 1142,67 \\
\hline
\end{tabular}

Notas: (a) À exceção do coeficiente estimado para a variável binária indígena, todos os demais parâmetros das equações ajustadas para funcionários públicos e empregados do setor privado cca são estatisticamente significativos, a um nível de significância de $1 \%$. Os coeficientes estimados para a variável indígena revelaram-se não significativos porque este grupo possui uma amostra muito pequena, que não permite detectar como estatisticamente significativas as diferenças observadas.

(b) A probabilidade caudal do teste $F$ é sempre inferior a $0,01 \%$, o que permite rejeitar a hipótese de que o conjunto de variáveis explanatórias incluídas na regressão não afeta o rendimento.

(c) As estimativas dos coeficientes das equações de rendimento ajustadas para cada grupo revelam-se estatisticamente diferentes, de acordo com o teste de Chow.

Fonte: Elaboração dos autores.

Era de esperar que, no setor público, mulheres e homens portadores de um mesmo conjunto de características auferissem o mesmo salário. Elas, entretanto, não apenas recebem cerca de $28,3 \%$ menos no setor público, como sofrem maior discriminação neste segmento, já que no setor privado seu rendimento esperado é $22 \%$ inferior ao dos homens. ${ }^{18}$

(18) Nos demais anos da série também se observa que a discriminação salarial contra mulheres é maior no setor público. O teste para a hipótese nula de que o coeficiente estimado para a variável sexo é igual para os dois grupos, a um nível de significância de 1\%, é significativo em todos os anos, exceto 1993. 
Supõe-se que as mulheres tenham as mesmas chances de ingresso na carreira pública que os homens, uma vez que o processo de seleção dos concursos públicos deveria ser neutro quanto ao sexo do indivíduo. De fato, como havíamos visto no item anterior, a proporção de mulheres entre os funcionários públicos supera com certa folga aquela observada entre os empregados do setor privado cca. No entanto, a progressão profissional dentro da carreira pública está sujeita à discriminação, pois certos cargos dependem de indicação (cargos de chefia e de confiança, por exemplo). Assim, a discriminação salarial por gênero observada na carreira pública deve estar associada, em grande medida, à menor presença de mulheres em cargos do topo da hierarquia da administração pública.

Os coeficientes relativos à idade diferem entre os grupos, mas a idade para a qual o rendimento estimado passa por um máximo é relativamente próxima: 55 anos para funcionários públicos e 53,6 anos para empregados do setor privado cca. De fato, o comportamento da variação do rendimento em função da idade é semelhante nos dois casos. A Gráfico 2 mostra como o valor de $\hat{Y}$ (estimativa do logaritmo neperiano do rendimento mensal de todos os trabalhos) varia com a idade, para cada grupo, considerando uma pessoa com o tempo semanal de trabalho médio e a escolaridade média de seu grupo e pertencente à categoria básica dos demais fatores analisados. Embora as parábolas estejam em níveis distintos - pois o intercepto da função é 5,71 para funcionários públicos e 5,08 para empregados do setor privado cca - elas apresentam curvaturas parecidas.

Gráfico 2

Variação de $\hat{Y}$ em função da idade, para funcionários públicos e empregados do setor privado cca, em 2005

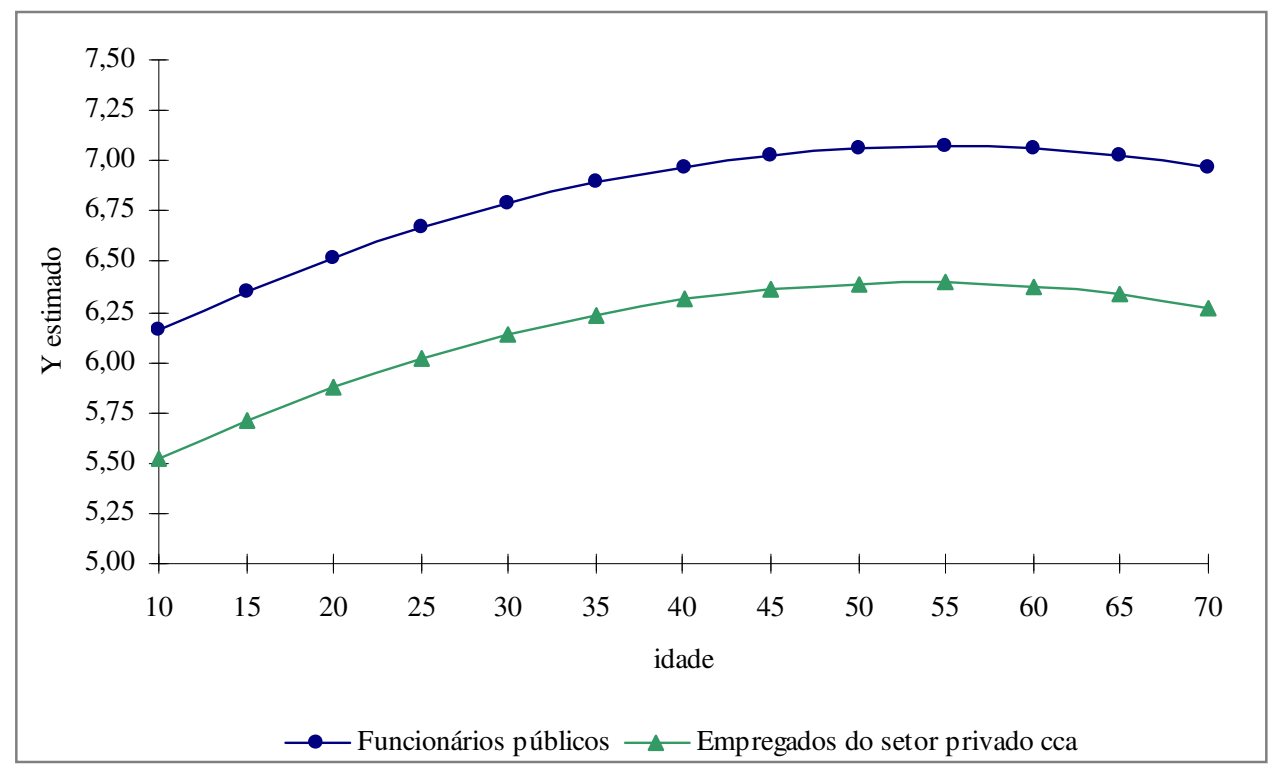

Fonte: Elaboração dos autores. 
Os coeficientes das duas variáveis associadas à escolaridade permitem calcular as taxas de retorno por ano de estudo quando ela é inferior a 9 anos, que são $6,21 \%$ para funcionários públicos e 2,83\% para empregados do setor privado cca, e também as taxas de retorno quando a escolaridade ultrapassa o limiar dos 9 anos, que são, respectivamente, 13,32\% e 13,97\%. Constata-se, assim, que o crescimento do rendimento em função da escolaridade é muito mais intenso quando esta ultrapassa o limiar dos 9 anos de estudo. Ademais, até os 9 anos de estudo, os funcionários públicos têm mais facilidade em converter educação em renda. A partir dos 9 anos de estudo, essa situação se inverte: os funcionários do setor privado obtêm maior retorno para cada ano adicional de estudo. Embora estas diferenças nas taxas de retorno à escolaridade, antes e após 9 anos de estudo, entre funcionários públicos e empregados do setor privado cca sejam pequenas, elas conservam seu sentido em todos os anos da série, o que revela um padrão bem definido.

No setor privado, o preto ganha, em média, $11,4 \%$ menos que o branco. No setor público, seu salário é $8,6 \%$ menor. O trabalhador pardo recebe respectivamente $9,6 \%$ e $8,7 \%$ menos que o trabalhador branco nos setores privado e público. Não há, no entanto, base segura para afirmar que a discriminação por cor é maior no setor privado: a diferença no coeficiente estimado entre os grupos para a variável binária preto é significativa apenas a um nível de significância superior a 20,54\%; no caso da variável pardo, a hipótese de que os coeficientes estimados são iguais só poderia ser rejeitada ao se considerar níveis de significância superiores a 43,04\%.

A pessoa de referência no domicílio ganha $13,8 \%$ a mais se for funcionário público e $16,1 \%$ a mais se está empregada no setor privado cca, em relação às demais pessoas do domicílio.

Em relação à região do país, a Nordeste é a que pior remunera funcionários públicos e empregados do setor privado cca. Os funcionários públicos mais bem pagos são os do Centro-Oeste e os paulistas, que recebem respectivamente $38,3 \%$ e $24,4 \%$ mais que seus equivalentes nordestinos. Dentre os trabalhadores formais do setor privado alocados em Serviços, o estado de São Paulo e as regiões Centro-Oeste e Sul oferecem rendimentos, em média, 39,6\%, $28,8 \%$ e $27,7 \%$ maiores que aqueles pagos no Nordeste, respectivamente.

Em relação à localização do domicílio, os funcionários públicos residentes em áreas urbanas não metropolitanas recebem 24,9\% menos que funcionários públicos de áreas metropolitanas. No caso de empregados do setor privado cca, o rendimento médio é 10,2\% menor quando se transita de área metropolitana para urbana não metropolitana. Logo, os empregados do setor privado cca conservam uma proporção maior de seu rendimento quando transitam de áreas metropolitanas 
para urbanas não metropolitanas, em relação a funcionários públicos submetidos à mesma mudança.

A elasticidade do rendimento mensal em relação ao tempo semanal de trabalho é estimada em 0,496, para funcionários públicos, e 0,224, para empregados do setor privado cca. $\mathrm{O}$ fato de ser menor que 1 indica que $\mathrm{o}$ prolongamento do tempo de trabalho é feito com prejuízo da produtividade e/ou por meio de trabalhos secundários pior remunerados. No caso de empregados do setor privado cca, o valor é substancialmente menor que 1 , revelando um prejuízo bem maior.

É possível que uma parcela da diferença de rendimentos observada entre os grupos resulte de características pessoais não incluídas no modelo de regressão - como inteligência, ambição, riqueza da família -, mas que influem no rendimento pessoal. Assim, o componente do hiato de rendimentos associado à diferença nos coeficientes estimados - o efeito de parâmetros - pode estar superestimado.

\subsection{Decomposição de Blinder-Oaxaca}

$\mathrm{Na}$ tentativa de compreender o fenômeno de distanciamento do rendimento de funcionários públicos e empregados do setor privado cca, procedeu-se à decomposição do hiato salarial entre os dois grupos, segundo a metodologia de Blinder-Oaxaca. O resultado deste procedimento pode ser observado na Tabela 6.

Tabela 6

Decomposição da diferença entre as médias dos logaritmos dos rendimentos de funcionários públicos e empregados do setor privado cca, no Brasil, de 1992 a 2005

\begin{tabular}{l|c|c|c|c}
\hline Ano & Efeito de médias & \% do total & $\begin{array}{c}\text { Efeito de } \\
\text { parâmetros }\end{array}$ & \% do total \\
\hline 1992 & $-0,236$ & 103,97 & 0,009 & $-3,97$ \\
\hline 1993 & $-0,258$ & 95,81 & $-0,011$ & 4,19 \\
\hline 1995 & $-0,259$ & 77,95 & $-0,073$ & 22,05 \\
\hline 1996 & $-0,241$ & 87,98 & $-0,033$ & 12,02 \\
\hline 1997 & $-0,259$ & 83,16 & $-0,052$ & 16,84 \\
\hline 1998 & $-0,250$ & 73,22 & $-0,091$ & 26,78 \\
\hline 1999 & $-0,253$ & 71,97 & $-0,099$ & 28,03 \\
\hline 2001 & $-0,280$ & 66,51 & $-0,141$ & 33,49 \\
\hline 2002 & $-0,279$ & 64,40 & $-0,154$ & 35,60 \\
\hline 2003 & $-0,287$ & 66,94 & $-0,142$ & 33,06 \\
\hline 2004 & $-0,271$ & 65,23 & $-0,144$ & 34,77 \\
\hline 2005 & $-0,277$ & 62,47 & $-0,167$ & 37,53 \\
\hline
\end{tabular}

Fonte: Elaboração dos autores. 
Observa-se que tanto o efeito de médias quanto o de parâmetros cresceram de 1992 para 2005. Entretanto, como este último cresceu mais intensamente, aumentou sua participação na explicação da diferença total das médias dos logaritmos dos rendimentos das duas categorias de trabalhadores. O Gráfico 3 mostra uma clara tendência de diminuição da participação do efeito de médias. Tende a diminuir, portanto, a parcela do hiato de rendimentos que pode ser explicada pelas diferentes características das duas categorias de pessoas ocupadas.

Gráfico 3

Participação (em \%) do efeito de médias e do efeito de parâmetros na decomposição da diferença entre as médias dos logaritmos dos rendimentos de funcionários públicos e empregados do setor privado cca, no Brasil, de 1992 a 2005

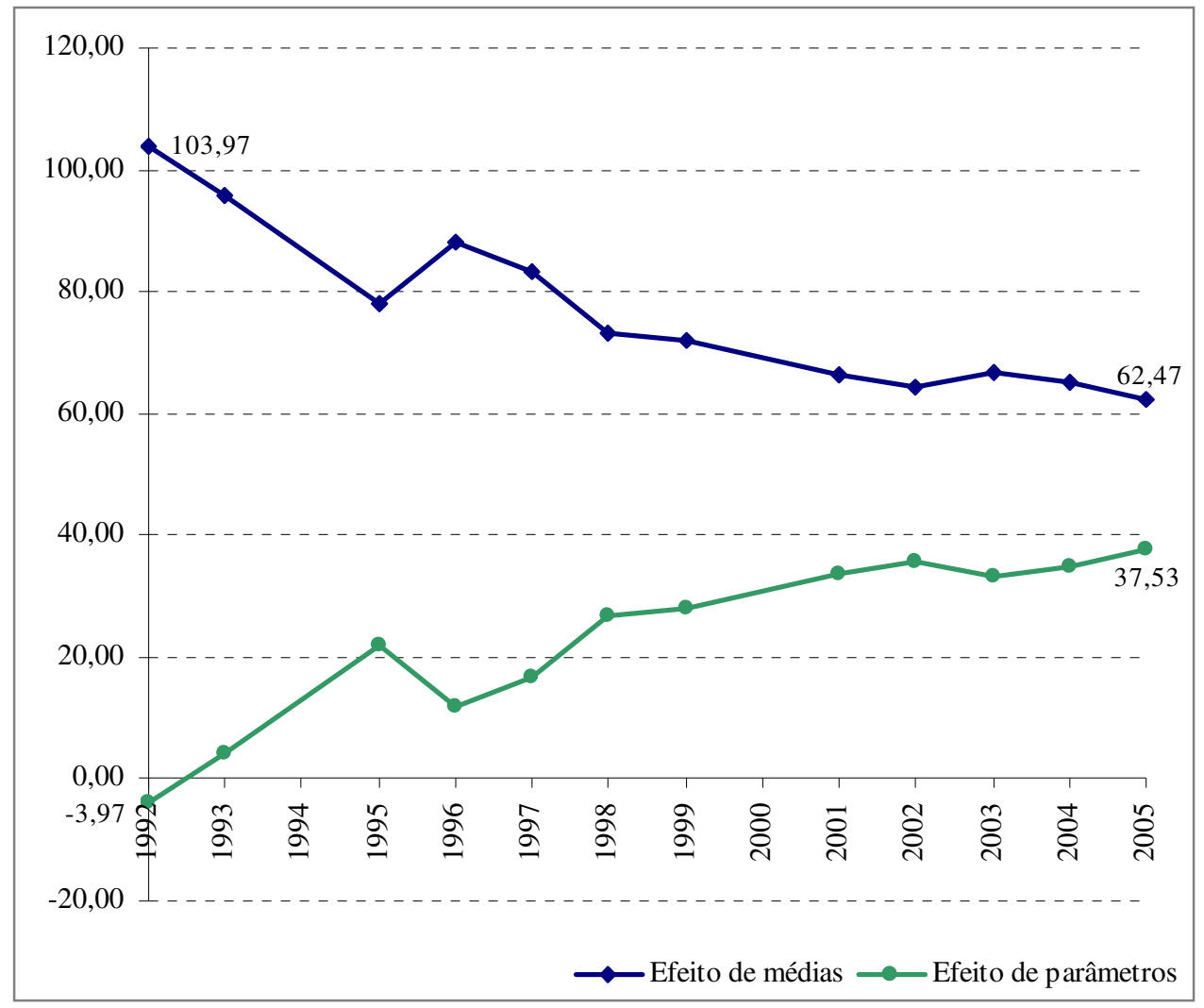

Fonte: Elaboração dos autores.

$\mathrm{Na}$ tentativa de entender a razão da diminuição da participação do efeito de médias na decomposição da diferença de rendimentos entre os dois grupos, decompôs-se o efeito total de médias nos fatores determinantes do rendimento pessoal, em 2005. 
A Tabela 7 mostra que os fatores que mais contribuem para a geração do efeito de médias são escolaridade e idade, sendo que ambos atuam favoravelmente à geração do hiato de rendimentos em prol de funcionários públicos. De fato, vimos na seção 3.1.1 que as características que mais distinguem empregados em serviços do setor privado cca em relação a funcionários públicos são escolaridade e idade, sendo estes últimos, em média, mais velhos e mais qualificados que aqueles. Em relação às demais características, os indivíduos dos dois grupos são, em média, mais parecidos.

Tabela 7

Decomposição do efeito total de médias nos fatores determinantes do rendimento pessoal, em 2005

\begin{tabular}{l|c|c}
\hline Fator & Efeito de médias do fator & $\begin{array}{c}\text { Participação percentual do fator } \\
\text { no efeito total de médias }\end{array}$ \\
\hline Sexo & 0,0408 & $-14,71$ \\
\hline Idade & $-0,1412$ & 50,93 \\
\hline Escolaridade & $-0,2546$ & 91,83 \\
\hline Cor & 0,0025 & $-0,90$ \\
\hline Região & 0,0340 & $-12,28$ \\
\hline Condição na família & $-0,0080$ & 2,90 \\
\hline Log do no de horas semanais de trabalho & 0,0349 & $-12,60$ \\
\hline Localização do domicílio & 0,0143 & $-5,16$ \\
\hline Total & $-0,2772$ & 100,00 \\
\hline
\end{tabular}

Fonte: Elaboração dos autores.

Na Tabela 8, a seguir, são apresentados os valores do efeito de médias, total e para cada um dos fatores determinantes do rendimento pessoal, de 1992 a 2005. Na Tabela 9 estão as participações destes valores na diferença total das médias dos logaritmos dos rendimentos de funcionários públicos e empregados do setor privado cca.

A Tabela 8 mostra que o efeito de médias do fator sexo era de 0,056 em 1992 e caiu para 0,041 em 2005. Este fator atenua o hiato salarial a favor de funcionários públicos. Por haver diminuído ao longo do período, evidencia-se que, embora continue existindo uma maior proporção de mulheres entre os funcionários públicos, em relação aos empregados em serviços do setor privado, esta diferença era maior em 1992. ${ }^{19}$ Destarte, a participação do efeito de médias do fator sexo na diferença total de médias dos logaritmos dos rendimentos dos dois grupos diminuiu de 1992 para 2005, como atesta a Tabela 9.

(19) A proporção de mulheres entre os funcionários públicos manteve-se próxima de $60 \%$ entre 1992 e 2005, ao passo que para os empregados do setor privado cca passou de cerca de 38\% em 1992 para aproximadamente $44 \%$ em 2005. 
Tabela 8

Efeito de médias, total e por fator, da diferença entre as médias dos logaritmos do rendimento de funcionários públicos e de empregados do setor privado cca, no Brasil, de 1992 a 2005

\begin{tabular}{l|l|l|l|l|l|l|c|c|c|}
\hline Ano & Sexo & Idade & Escolaridade & Cor & Região & $\begin{array}{c}\text { Condição na } \\
\text { família }\end{array}$ & $\begin{array}{c}\text { Log do } \\
\text { número de } \\
\text { horas semanais } \\
\text { de trabalho }\end{array}$ & $\begin{array}{c}\text { Localização do } \\
\text { domicílio } \\
\text { Total }\end{array}$ \\
\hline 1992 & 0,056 & $-0,100$ & $-0,318$ & 0,001 & 0,045 & 0,007 & 0,054 & 0,019 \\
\hline 1993 & 0,056 & $-0,104$ & $-0,332$ & $-0,002$ & 0,046 & 0,006 & 0,050 & 0,023 & $-0,236$ \\
\hline 1995 & 0,062 & $-0,117$ & $-0,345$ & 0,000 & 0,062 & 0,005 & 0,048 & 0,026 \\
\hline 1996 & 0,058 & $-0,118$ & $-0,320$ & 0,001 & 0,064 & 0,003 & 0,045 & 0,026 & $-0,259$ \\
\hline 1997 & 0,062 & $-0,130$ & $-0,316$ & 0,000 & 0,052 & 0,002 & 0,045 & 0,027 & $-0,259$ \\
\hline 1998 & 0,056 & $-0,126$ & $-0,311$ & 0,000 & 0,057 & 0,000 & 0,043 & 0,031 & $-0,250$ \\
\hline 1999 & 0,053 & $-0,127$ & $-0,299$ & 0,001 & 0,054 & 0,002 & 0,035 & 0,028 \\
\hline 2001 & 0,049 & $-0,138$ & $-0,295$ & 0,001 & 0,043 & $-0,003$ & 0,038 & 0,025 & $-0,253$ \\
\hline 2002 & 0,042 & $-0,138$ & $-0,290$ & 0,001 & 0,046 & $-0,003$ & 0,043 & 0,020 & $-0,280$ \\
\hline 2003 & 0,041 & $-0,140$ & $-0,270$ & 0,003 & 0,039 & $-0,005$ & 0,030 & 0,015 \\
\hline 2004 & 0,039 & $-0,134$ & $-0,268$ & 0,003 & 0,041 & $-0,005$ & 0,035 & 0,019 \\
\hline
\end{tabular}


Tabela 9

Participação percentual do efeito de médias total e por fator na diferença entre as médias dos logaritmos do rendimento de funcionários públicos e empregados do setor privado cca, de 1992 a 2005

\begin{tabular}{l|l|l|l|l|l|c|c|c|c}
\hline Ano & Sexo & Idade & Escolaridade & Cor & Região & $\begin{array}{c}\text { Condição na } \\
\text { família }\end{array}$ & $\begin{array}{c}\text { Log do } \\
\text { número de } \\
\text { horas semanais } \\
\text { de trabalho }\end{array}$ & $\begin{array}{c}\text { Localização do } \\
\text { domicílio }\end{array}$ & $\begin{array}{c}\text { Participação } \\
\text { do efeito de } \\
\text { médias }\end{array}$ \\
\hline 1992 & $-24,81$ & 44,10 & 140,29 & $-0,28$ & $-19,70$ & $-3,31$ & $-23,90$ & $-8,42$ \\
\hline 1993 & $-20,67$ & 38,71 & 123,01 & 0,72 & $-16,90$ & $-2,31$ & $-18,39$ & $-8,36$ & 103,97 \\
\hline 1995 & $-18,73$ & 35,32 & 103,77 & $-0,02$ & $-18,68$ & $-1,49$ & $-14,38$ & $-7,85$ & 77,94 \\
\hline 1996 & $-21,07$ & 42,88 & 116,55 & $-0,42$ & $-23,22$ & $-1,11$ & $-16,32$ & $-9,31$ & 87,98 \\
\hline 1997 & $-19,90$ & 41,60 & 101,41 & 0,03 & $-16,61$ & $-0,51$ & $-14,35$ & $-8,50$ & 83,16 \\
\hline 1998 & $-16,32$ & 36,88 & 91,18 & $-0,03$ & $-16,77$ & $-0,04$ & $-12,61$ & $-9,07$ & 73,22 \\
\hline 1999 & $-15,09$ & 36,10 & 84,93 & $-0,21$ & $-15,39$ & $-0,62$ & $-9,95$ & $-7,82$ & 71,97 \\
\hline 2001 & $-11,59$ & 32,81 & 69,91 & $-0,13$ & $-10,17$ & 0,61 & $-9,12$ & $-5,83$ & 66,51 \\
\hline 2002 & $-9,76$ & 31,76 & 66,97 & $-0,33$ & $-10,56$ & 0,80 & $-9,81$ & $-4,66$ & 64,40 \\
\hline 2003 & $-9,52$ & 32,55 & 62,88 & $-0,70$ & $-9,08$ & 1,24 & $-6,93$ & $-3,50$ & 66,94 \\
\hline 2004 & $-9,39$ & 32,26 & 64,60 & $-0,69$ & $-9,90$ & 1,21 & $-8,38$ & $-4,47$ & 65,23 \\
\hline 2005 & $-9,19$ & 31,81 & 57,37 & $-0,56$ & $-7,67$ & 1,81 & $-7,87$ & $-3,22$ & 62,47 \\
\hline
\end{tabular}


Em relação ao fator idade, observa-se que o efeito de médias a ele atribuído contribui para a geração do hiato de rendimentos a favor de funcionários públicos, em todos os anos da série, o que significa que, em todo o período analisado, os funcionários públicos são, em média, mais velhos que os empregados do setor privado cca. O valor absoluto deste fator apresentou tendência de aumento entre 1992 e 2005, mas como o hiato total de rendimentos entre as duas categorias aumentou mais intensamente, sua participação diminuiu ao longo do período.

No que tange ao logaritmo do número de horas semanais de trabalho, houve diminuição progressiva de seu efeito de médias, o qual já era pequeno. Assim, o impacto deste fator na geração do hiato de rendimentos a favor de funcionários públicos se deve essencialmente a seu efeito de parâmetros.

O valor absoluto do efeito de médias do fator escolaridade cresceu de 1992 para 1995, mas diminuiu de 1997 em diante. Sua participação na diferença total de rendimentos observada diminuiu significativamente: era superior a $140 \%$ em 1992 e reduziu-se a um valor inferior a 50\% em 2005. Assim, embora continue sendo importante para explicar o hiato de rendimentos a favor de funcionários públicos, o efeito de médias do fator escolaridade perdeu importância considerável. Dentre os fatores determinantes do rendimento pessoal, foi o que mais contribuiu para a diminuição da participação do efeito de médias, como um todo, na decomposição da diferença de rendimentos entre os dois grupos, de 1992 a 2005 .

$\mathrm{Na}$ Tabela 10 temos as médias de anos de estudo, em todos os anos da série, de funcionários públicos e empregados em serviços do setor privado cca.

Tabela 10

Média de anos de estudo para funcionários públicos e empregados do setor privado cca

\begin{tabular}{l|c|c|c}
\hline \multirow{2}{*}{ Ano/Variável } & \multicolumn{3}{|c}{ Anos de estudo } \\
\cline { 2 - 4 } & Funcionário público (A) & $\begin{array}{c}\text { Empregado do setor } \\
\text { priv. cca (B) }\end{array}$ & (A) - (B) \\
\hline 1992 & 10,82 & 7,57 & 3,24 \\
\hline 1993 & 10,86 & 7,74 & 3,12 \\
\hline 1995 & 10,94 & 7,87 & 3,07 \\
\hline 1996 & 11,00 & 8,15 & 2,85 \\
\hline 1997 & 11,20 & 8,33 & 2,87 \\
\hline 1998 & 11,21 & 8,53 & 2,68 \\
\hline 1999 & 11,28 & 8,68 & 2,60 \\
\hline 2001 & 11,51 & 9,01 & 2,51 \\
\hline 2002 & 11,61 & 9,24 & 2,37 \\
\hline 2003 & 11,76 & 9,41 & 2,35 \\
\hline 2004 & 11,87 & 9,60 & 2,27 \\
\hline 2005 & 11,97 & 9,79 & 2,18 \\
\hline
\end{tabular}

Fonte: Elaboração dos autores. 
Observamos que, embora os dois grupos tenham apresentado aumento contínuo no número médio de anos de estudo de 1992 a 2005, tal aumento foi mais intenso para os empregados do setor privado. Como resultado, a diferença de médias de anos de estudo entre os dois grupos diminuiu progressivamente no período; era de 3,24 anos em 1992 e passou a ser de 2,18 anos em 2005. Isto explica a perda de importância absoluta e relativa do efeito de médias do fator escolaridade.

\section{Conclusões}

Ao longo deste trabalho, constatou-se a existência de um hiato salarial entre funcionários públicos e empregados do setor privado cca alocados no setor de serviços, no Brasil, a favor dos primeiros. Entre 1992 e 2005, período que em se concentrou o presente estudo, os empregados do setor privado cca auferiram, em média, um rendimento equivalente a $62,6 \%$ daquele recebido por funcionários públicos estatutários.

Constatou-se, ademais, que tal hiato ampliou-se de forma não desprezível no período considerado. Em 1992, os empregados do setor privado cca auferiam um rendimento cerca de $20 \%$ inferior ao recebido por funcionários públicos. Em 2005, esta diferença havia se ampliado para aproximadamente $36 \%$.

Em parte, o hiato de rendimento entre funcionários públicos e empregados do setor privado cca se deve à heterogeneidade entre estas duas categorias de trabalhadores no tocante às suas características produtivas. Os empregados do setor privado cca ganham menos principalmente porque são, em média, mais jovens e menos qualificados. Ademais, seu ingresso precoce no mercado de trabalho, em atividades pouco qualificadas, contribui para o menor rendimento médio do grupo.

Por outro lado, os coeficientes das equações de rendimento estimadas para as duas categorias revelaram-se estatisticamente distintos, mesmo tendo sido utilizados controles para região e tipo de inserção no mercado de trabalho. Estas evidências reforçam a hipótese de segmentação entre os mercados de trabalho público e privado. As taxas de retorno por ano de estudo, por exemplo, são, até os 9 anos de estudo, superiores para funcionários públicos, indicando que estes têm mais facilidade em converter educação em renda. A partir dos 9 anos, porém, essa situação se inverte: os funcionários do setor privado obtêm maior retorno para cada ano adicional de estudo. Isto revela que os processos de determinação salarial nos setores público e privado, isto é, os critérios de remuneração e os mecanismos de incentivo, são bastante distintos, sendo, portanto, distintos os pesos atribuídos aos atributos produtivos dos trabalhadores em cada caso. 
Foram particularmente inesperados os valores obtidos para os coeficientes da variável sexo. Eles revelaram que a discriminação contra mulheres é maior na carreira pública. Isto sugere que os princípios de transparência e imparcialidade que deveriam ser obedecidos na contratação de funcionários públicos não são efetivamente seguidos ao longo da carreira.

A decomposição do hiato salarial entre os dois grupos no componente que se deve a diferenças de atributos - escolaridade, idade, distribuição geográfica - e no componente residual, que expressa a segmentação entre os dois mercados de trabalho, revelou que tanto o efeito de médias quanto o de parâmetros cresceram de 1992 para 2005. Entretanto, como este último cresceu mais intensamente, aumentou sua participação na explicação da diferença total das médias dos logaritmos dos rendimentos das duas categorias de trabalhadores, diminuindo, portanto, a parcela do hiato de rendimentos que pode ser explicada pelas diferentes características das duas categorias de pessoas ocupadas.

O fator escolaridade foi o principal responsável pela redução da participação do efeito de médias no hiato salarial entre os grupos, pois seu valor absoluto apresentou expressiva queda de 1992 a 2005 e este fator é o mais importante para a geração do efeito de médias.

O efeito de médias do fator escolaridade reduziu-se porque a diferença de médias de anos de estudo entre os dois grupos diminuiu progressivamente de 1992 a 2005, ainda que ambas as categorias tenham apresentado aumento contínuo no número médio de anos de estudo no período.

A elevação do nível educacional dos trabalhadores em serviços do setor privado formal não impediu, entretanto, que seu rendimento médio sofresse queda contínua entre 1998 e 2003. Isto indica que estes trabalhadores não conseguiram converter a melhoria alcançada em seus atributos produtivos em ganhos salariais, seja porque não conseguiram repor as perdas salariais causadas pela inflação, seja porque as remunerações pagas nas novas vagas criadas neste setor são inferiores às verificadas nas antigas ocupações. Assim, mesmo dispondo de maior capacidade de negociação salarial que os trabalhadores informais, estes trabalhadores não conseguiram evitar um achatamento de seus salários.

É surpreendente que, no mesmo período em que os empregados formais do setor terciário privado tiveram crescimento de $4 \%$ em sua renda, a renda média dos funcionários públicos tenha crescido $35 \%$. Elencamos duas hipóteses para este fenômeno.

Por um lado, a estabilidade do emprego público tornou os trabalhadores deste segmento menos vulneráveis às vicissitudes pelas quais passou a economia brasileira nos anos 1990, ao passo que, no setor privado, os trabalhadores enfrentaram ondas de demissão e posterior recontratação a menores salários. 
Por outro lado, podemos encontrar uma explicação para o aumento da renda média dos funcionários públicos no critério utilizado pelos governantes para, ao longo do período estudado, realizar o saneamento deste setor. Optou-se pela diminuição de cargos de suporte e a manutenção de profissionais considerados de áreas finalísticas, isto é, responsáveis pela formulação, fomento e execução das tarefas dos órgãos a que pertencem. Como conseqüência, a reforma empreendida eliminou principalmente cargos de menor qualificação e menores salários, contribuindo para o aumento da escolaridade média e do rendimento médio do setor.

\section{Referências bibliográficas}

BERNDT, E. R. Analyzing determinants of wages and measuring discrimination: dummy variables in regression models. In: BERNDT, E. R. The practice of econometrics: classic and contemporary. Addison-Wesley, 1991. cap. 5, p. 150-223.

CAMPANTE, F. R.; CRESPO, A. R. V.; LEITE, P. G. Desigualdade salarial entre raças no mercado de trabalho urbano brasileiro: aspectos regionais. Revista Brasileira de Economia, Rio de Janeiro: v. 58, n. 2, p. 185-210, abr./jun. 2004.

CORSEUIL, C. H.; FOGUEL, M. N. Uma sugestão de deflatores para rendas obtidas a partir de algumas pesquisas domiciliares do IBGE. Rio de Janeiro: Ipea, jul. 2002. 8p. (Texto para discussão, n. 897).

HOFFMANN, R. A distribuição da renda no Brasil no período 1992-2001. Economia e Sociedade, Campinas: Instituto de Economia da Unicamp, n. 19, p. 213-235, jul./dez. 2002.

Income distribution in Brazil and the regional and sectoral contrasts. In: GUILHOTO, J. J. M.; HEWINGS, G. J. D. (Org.). Structure and structural change in the Brazilian economy. Aldershot: Ashgate, 2001. cap. 5, p. 85-106.

- Mensuração da desigualdade e da pobreza no Brasil. In: HENRIQUES, R.

(Org.). Desigualdade e Pobreza no Brasil. Rio de Janeiro: IPEA, 2000. cap. 3, p. 81-107.

Distribuição de renda: medidas de desigualdade e pobreza. São Paulo: Ed. da USP, 1998. cap. 4, p. 99-152.

; NEY, M. G. Desigualdade, escolaridade e rendimentos na agricultura, indústria e serviços, de 1992 a 2002. Economia e Sociedade, Campinas, v. 13, n. 2 (23), p. 51-79, jul./dez. 2004.

; SIMÃO, R. C. S. Determinantes do rendimento das pessoas ocupadas em Minas Gerais em 2000: o limiar no efeito da escolaridade e as diferenças entre mesorregiões. Nova Economia, v. 15, n. 2, p. 35-62, maio/ago. 2005.

LEME, M. C. S.; WAJNMAN, S. Tendências de coorte nos diferenciais de rendimentos por sexo. In: HENRIQUES, R. (Org.). Desigualdade e pobreza no Brasil. Rio de Janeiro: Ipea, 2000. cap. 9, p. 251-270. 
MARCONI, N. Uma breve comparação entre os mercados de trabalho do setor público e privado. Revista do Serviço Público, Brasília: ENAP, ano 48, n. 1, p. 127-146, jan./mar. 1997.

A evolução do perfil da força de trabalho e das remunerações nos setores público e privado ao longo da década de 1990. Revista do Serviço Público, Brasília: ENAP, ano 54, n. 1, p. 7-43, jan./mar. 2003.

Gap between public and private wages and wages determination in the public sector. Revista de Economia Política, São Paulo, editora 34, v. 24, n. 2, p. 257-279, abr./jun. 2004.

MENEZES-FILHO, N.; FERNANDES, R.; PICCHETTI, P. A evolução da distribuição de salários no Brasil: fatos estilizados para as décadas de 80 e 90. In: HENRIQUES, R. (Org.). Desigualdade e pobreza no Brasil. Rio de Janeiro: Ipea, 2000. cap. 8, p. 231-250.

NAJBERG, S.; MORAES, R. M.; IKEDA, M. Participação dos empregos do setor público no mercado de trabalho. Informe-se, Rio de Janeiro (RJ), Área de Assuntos Fiscais e de Emprego, BNDES, n. 42, jun. 2002. 8p.

NEY, M.G.; HOFFMANN, R. Desigualdade de renda na agricultura: o efeito da posse da terra. Economia, Niterói (RJ), Anpec, v. 4, n. 1, p. 113-152, jan./jun. 2003.

RAMALHO, M.; URANI, A. A administração pública como empregadora: uma avaliação da década de 80. Rio de Janeiro: Ipea, abr. 1995. 22p. (Série Seminários, n. 5/95).

RAMOS, L.; VIEIRA, M. L. Determinantes da desigualdade de rendimentos no Brasil nos anos 90: discriminação, segmentação e heterogeneidade dos trabalhadores. In: HENRIQUES, R. (Org.). Desigualdade e pobreza no Brasil. Rio de Janeiro: Ipea, 2000. cap. 6, p. 159-176.

ROCHA, S. A investigação do rendimento na PNAD - comentários e sugestões à pesquisa nos anos 2000. Rio de Janeiro: Ipea, ago. 2002. 19p. (Texto para discussão, n. 899).

SOARES, S. S. D. O perfil da discriminação no mercado de trabalho - homens negros, mulheres brancas e mulheres negras. Brasília: Ipea, nov. 2000. 26p. (Texto para Discussão, n. 769).

TAVARES, M. C. A economia política do Real. In: MERCADANTE, A. (Org.). $O$ Brasil pós-Real: a política econômica em debate. Campinas (SP): Instituto de Economia da Universidade Estadual de Campinas, 1997. p. 101-129.

VAZ, D. V. Rendimento em serviços nos anos 90: o contraste entre funcionários públicos e privados. Dissertação (Mestrado em Economia)-Instituto de Economia, Unicamp, Campinas, 2005. $95 f$.

ZUCCHI, J. D.; HOFFMANN, R. Diferenças de renda associadas à cor: Brasil, 2001. Pesquisa e Debate 24, São Paulo, PUC-SP, v. 15, n, 1, p. 107-129, 2004. 